\title{
A Study on Behaviour of Cohession Less Soil with Square Plate
}

\author{
Ahmed Mohmed Ahmed Blash ${ }^{1}$, Hussein Mohmed Hussein Ahmeed ${ }^{2}$ \\ ${ }^{1} \mathrm{PhD}$ Students, 1Department of Civil Engineering, Acharya Nagarjuna University, Guntur, Andhra Pradesh, India \\ ${ }^{2}$ Department Civil Engineering Higher Institute of Sciences and Technology -Aljufra, Sokna-Libya
}

\begin{abstract}
Many studies on the distribution of contact pressure have been made when a flexible or rigid footing is founded on soil. Many investigators have proposed bearing capacity theories assuming the footing to be rigid. But all theories have been based on the assumption that the footing will always be in contact with the soil. In this paper numerical analysis is carried out to separate foundations with partial contact with soil form those with full contact. The factors determining the contact of footing with the soil are plan dimensions, thickness and elastic properties of the material of the footing, modulus of sub grade reaction of the soil supporting it, the column to footing width ratio and eccentricity of loading. Multiple linear regression analysis is carried out to develop an equation for critical relative rigidity (CRR) in terms of the other parameters influencing it. Based on the equation, a single chart has been developed to find CRR for various combinations of the parameters influencing it. The conventional method of finding bending moment says that the maximum bending moment is independent of the relative rigidity of the footing(i.e. thickness of the footing and the modulus of sub grade reaction of the soil supporting it). But ANSYS 12.0 results show that bending moment depends on relative rigidity of footing also. Experimental work have been conducted to verify the values of maximum bending moment given by ANSYS.The results derived from the tests that are performed at the laboratory are typically a specific problem and they are difficult to extend, and to develop to field problems due to the different material or the geometric parameters used.
\end{abstract}

Keywords: ANSYS 12.0, Soil, footing, Shell 63, Analysis

\section{Introduction}

Ground improvement is the modification of foundation soils or project earth structures to provide better performance under operational loading conditions. Ground improvement methods are used increasingly for new projects to allow utilization of sites with poor subsurface conditions and to allow design and construction of needed projects despite poor subsurface conditions which formerly would have rendered the project economically unjustifiable or technically not feasible. The aforementioned crushed aggregates in the definite proportion are to be placed into the soil at regular intervals throughout the area of the land where the soil bearing capacity is to be improved

A Considerable progress has been made in the design of superstructure whereas the design of foundations still needs much attention. Very little work has been done on such problems perhaps due to complexity of soil structure interaction. As a result, the foundations are designed very conservatively. In soil structure interaction problems, a very high factor of safety (which is nothing but factor of ignorance)is used. Hence if considerable attention is imparted to the study of behavior of structure in relation with soil, it will lead to reduction of factor of safety to be adopted in the estimation of bearing capacity and bending moment. In most cases, the conventional methods are conservative and in some cases, surprisingly unsafe.

Knowledge of soil response is of primary importance in the development of rational design procedures for footing design. Many studies on the distribution of contact pressures have been made when a flexible or rigid footing is founded in soil. Many investigators have proposed bearing capacity theories assuming the footing to be rigid that is the footing will always be in contact with the soil, and there is no loss of contact at any part of the footing. But all these theories have been proposed without considering the partial area of contact of the footing with respect to the soil.

Conventional method of design of footings assumes that the footing is always in contact with the soil and the contact pressure distribution is linear. But practically, even concentrically loaded footings may loose contact with the soil, especially when a thin footing is resting on a very hard stratum.

The factors determining the contact of the footing with the soil are the plan dimensions, thickness and elastic properties of the material of the footing, modulus of sub grade reaction of the soil supporting it, the column to the footing width ratio and the eccentricity of the loading. For example, qualitatively it is known that when all other factors remain the same, a thin footing may loose contact whereas a thick footing may have full contact with the soil.

Similarly a footing supported on rock may loose contact whereas the same footing supported on soft clay may have full contact, but the critical number, which separates a footing may have full contact from that with partial contact, is yet to be established for different conditions. In this thesis an attempt is made to quantify the factors influencing the footing contact.

Apart from this, conventional method of calculating the bending moment on the footing assumes that the contact pressure is linear and bending moment is independent of the thickness of the footing and the modulus of sub grade reaction of the soil supporting it leading to conservative design and in some cases unsafe design. 


\section{International Journal of Science and Research (IJSR) \\ ISSN (Online): 2319-7064}

Index Copernicus Value (2013): 6.14 | Impact Factor (2015): 6.391

This paper aims to study the influence of Relative Rigidity (Rigidity of soil with footing), column to footing width ratio and eccentricity of loading of the footing on contact pressure. Graphs have been developed for the cases stated above. When the footing losses contact, the effective area of contact decreases, the pressure of the soil will be different that from the conventional assumption. This change in pressure leads to the increase or decrease of the maximum bending moment, which again depends on the magnitude of pressure and the span of the pressure diagram.

Conventional method of finding the bending moment says that, the maximum bending moment is independent of the Relative Rigidity (a term, which takes in to account both soil and the footing properties) of the footing (i.e., thickness of the footing and the modulus of sub grade reaction of the soil supporting the footing). So the present paper also aims to show that, Relative Rigidity of the footing very much influences the bending moment.

\section{Review of Literature}

Theory of plates on elastic foundation occupies a prominent place in modern engineering mechanics, since the soil exhibits a very complex behavior, it's response to external loads is idealized.

Number of investigators have done the work on footings founded on elastic support. But many of them have not considered lift phenomenon and the partial contact of footing with the soil.

Simplest approach is to assume that the foundation reaction can be proportional to the deflection at that point as per Winklerk's hypothesis (Winkler ,1867).

Gorge Gazetas(1982) has done analytical study of the behavior of rigid perfectly plastic circular foundation plate indenting an elastic two- parameter soil layer (Vlasov model) under the action of a statically increasing applied load.

Remeshbabu (1998) investigated the pull-out capacity and the load deformation behavior of the horizontal shallow anchor plate. Laboratory experiments have been conducted on anchors of different shapes (square, circular and strip) and embedded in medium dense \& dense sands. In addition, the effect of submergence of the soil above horizontal anchor plates has been investigated as well.

Ashraf Ghaly (1977) had recommended a general expression for the pull-out capacity of the vertical anchor plates based statically on the analysis of the experimental test results from the published literature. On similar lines and incorporating appropriate correction.

Only a few investigations, concerning the performance of the ultimate pull-out load in cohesion, were recorded in the model studies in laboratory. An example of this is Lidija Fargic and Pavao Marovic (2003) that discussed about the pull-out capacity of the anchors in the soil under the applied up-lift force.
E.J. Murray and James D. Geddes (2006) investigated into the vertical pull-out of the horizontal anchor plates in medium dense sand. As well, the investigation involved the factors in relation to the loaddisplacement by obtaining the response that were: the size and shape of plate, depth of embedment, sand density and plate surface roughness in laboratory. Vallanbah and Das(1987;1990) developed an iterative procedure to compute the value of ,,$\Upsilon^{\text {ee }}$ uniquely for a beam an elastic foundation problem. Straughan (1990) applied this concept to analyse plates on an elastic foundation using the difference method. Recently, C.V,Girija Vallanbah and A.Turhan Daloglu (1999) developed a new model using rectangular finite elements to represent the plate, along with a set of consistent stiffness matrices to represent the soil. They have solved the example problems and compared with the results obtained by few other researchers. Hence in this paper, an attempt has been made to find the maximum contact pressure in terms of the above mentioned factors and considering only the partial contact area. It is also known that the bending moment at a point on the foundation depends on the Relative Rigidity of the footing. An attempt is made to verify the above statement.

\section{Materials and Methods}

The ANSYS 12.0 computer program is large scale purpose finite element program which may use to solve several classes of engineering analysis. The analysis capabilities of ANSYS 12.0 include the ability to solve static and Dynamic structural analysis, steady state and transient heat transfer problems, mode frequency and buckling Eigen value problems, static or time varying magnetic analysis and various types of field and coupled field applications. The ANSYS 12.0 program does not require any special knowledge of system operation or computer programming in order to be used.

\subsection{ANSYS software}

ANSYS is a general purpose finite element modeling package for numerically solving a wide variety of mechanical problems. These problems include: static/dynamic structural analysis (both linear and non-linear), heat transfer and fluid problems, as well as acoustic and electromagnetic problems.

In ANSYS 12.0 library contains more than 100 elements. Elements having unique number and a prefix that defines its category.

A. Static Analysis: The applied loads and support conditions of the solid body do not change with time. Nonlinear material and geometrical properties such as plasticity, contact, creep, etc., are available.

B. Modal Analysis: This option concerns natural frequencies and modal shapes of a structure.

C. Harmonic Analysis: The response of a structure subjected to loads only exhibiting sinusoidal behaviour in time.

D. Transient Dynamic: The response of a structure subjected to loads with arbitrary behaviour in time. 


\section{International Journal of Science and Research (IJSR) \\ ISSN (Online): 2319-7064}

Index Copernicus Value (2013): 6.14 $\mid$ Impact Factor (2015): 6.391

E. Eigenvalue Buckling: This option concerns the buckling loads and buckling modes of a structure And can be used for one dimensional, two dimensional, three dimensional problems also. In general, a finite element solution may be broken into the following three stages. The first step in any analysis is specifying a job name and analysis title. Then to build the model PREPROCESSOR is used.

In this depending up on the model can select the element type, to that element real constants, and material properties can be defined, model can be prepared by using create option after that model can be created. Geometry can be prepared through key points, lines, areas, and volumes. After that mesh lines, areas, volumes as required.

[Solution phase is entered where the analysis type is specified. Elements used for the analysis]

\section{Shell 63 element}

SHELL63 has both bending and membrane capabilities. Both in-plane and normal loads are permitted. The element has six degrees of freedom at each node: translations in the nodal $x$, $\mathrm{y}$, and $\mathrm{z}$ directions and rotations about the nodal $\mathrm{x}, \mathrm{y}$, and $\mathrm{z}-$ axes. Stress stiffening and large deflection capabilities are included.

\section{A.Input Data}

The geometry, node locations, and the coordinate system for this element are shown in Figure.1: SHELL63 Geometry. The element is defined by four nodes, four thicknesses, an elastic foundation stiffness, and the orthotropic material properties. Orthotropic material directions correspond to the element coordinate directions. The element coordinate system orientation is as described in Coordinate Systems.

The thickness is assumed to vary smoothly over the area of the element, with the thickness input at the four nodes. If the element has a constant thickness, only TK(I) need be input. If the thickness is not constant, all four thicknesses must be input.

The elastic foundation stiffness (EFS) is defined as the pressure required to produce a unit normal deflection of the foundation. The elastic foundation capability is bypassed if EFS is less than, or equal to, zero.

For certain no homogeneous or sandwich shell applications, the following real constants are provided: RMI is the ratio of the bending moment of inertia to be used to that calculated from the input thicknesses. RMI defaults to 1.0. CTOP and CBOT are the distances from the middle surface to the extreme fibers to be used for stress evaluations. Both CTOP and CBOTare positive, assuming that the middle surface is between the fibers used for stress evaluation. If not input, stresses are based on the input thicknesses.

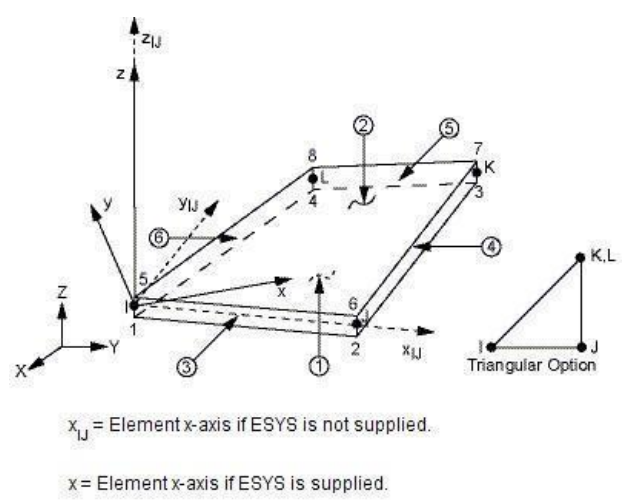

Figure 1:Shell 63 Element

B.Shell 63 input summary

Element name

Shell 63

NODES

I, J, K, L

\section{C.Real Constants}

TK(I), TK(J), TK(K), TK(L), EFS,

THETA,

RMI, CTOP, CBOT,

\section{D.Material Properties}

EX, EY, EZ, (PRXY, PRYZ, PRXZ

or NUXY, NUYZ, NUXZ), ALPX,

ALPY, ALPZ (or CTEX, CTEY,

CTEZ or THSX, THSY, THSZ),

DENS, GXY, DAMP

\section{E.Surface Loads Pressures -}

face 1 (I-J-K-L) (bottom, in +Zdirection), face 2 (I-J-K-L) (top, in-Z direction), face $3(\mathrm{~J}-\mathrm{I})$, face $4(\mathrm{~K}-\mathrm{J})$, face $5(\mathrm{~L}-\mathrm{K})$, face 6 (I-L)

\section{Body Loads}

\section{A. Temperatures --}

T1, T2, T3, T4, T5, T6, T7, T8

\section{B.MODELLING}

Step by step procedure for modeling, At first in preferences for structural engineering problems select structural option For discipline option select h-method.

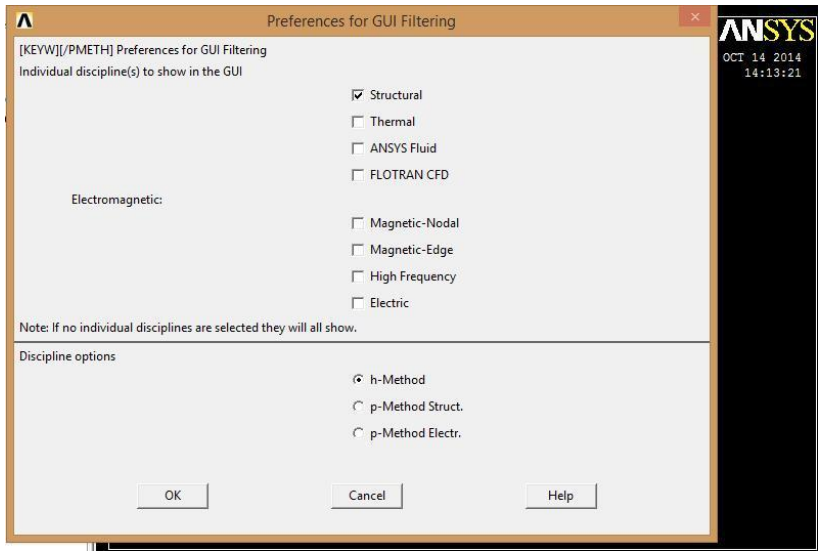

Figure 2: Step 1: pre-processor 


\section{International Journal of Science and Research (IJSR) \\ ISSN (Online): 2319-7064}

Index Copernicus Value (2013): 6.14 | Impact Factor (2015): 6.391

C.Element type: in this type of element is to be selected, i.e shell63 Element type -> add/edit/delete-> add -> shell 63

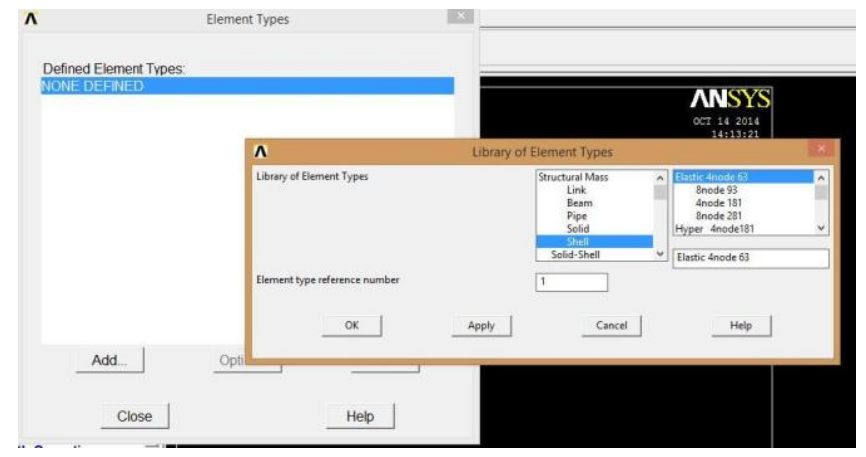

Figure 2: Element type

D.Real constants: For shell 63 element from the problem considered

Thickness of the plate can be taken as $300 \mathrm{~mm}$.

Distance from top to mid surface is 150 .

Distance from bottom to mid surface is 150 .

Elastic stiffness value can be calculated from relation of CRR. By trial and error process.

CRR value can be fixed. For that value elastic stiffness (ks) can be fixed.

Real constant-> add/edit/delete-> add -> shell 63-> values$>$ ok

\section{Development of Equation of Critical Relative Rigidity (CRR)}

In the present study, Multiple Linear Regression Analysis is carried out to develop the equation for Critical Relative Rigidity (CRR). And also based on the equation developed, a single graph is presented for CRR by taking all the factors in to consideration (i.e., both the soil and footing properties).

Robindavis. $\mathrm{P}(20)$ had done some work to separate foundations having partial contact with the soil from those with full contact. The relative rigidity of footing at which the footing starts losing contact (CRR) is found by him for different combinations of factors like eccentricity to footing width ratio, Poisson "es ratio of the material of the footing and column to footing width ratio. Also he developed charts for Critical Relative Rigidity.A footing of plan dimensions $3 \mathrm{~m} * 3 \mathrm{~m}$ and thickness $0.3 \mathrm{~m}$ was modelled using shell 63 element. For a particular Poisson ${ }^{\text {ee }}$ s ratio of the material of footing, eccentricity and a small value of modulus of subgrade reaction uniformly distributed load was applied through the columns having a particular column to footing width ratio and the deflection pattern was found in the solution. Since the modulus of subgrade reaction selected for the first trial is very small, the value of $\mathrm{R}$ is small and hence the footing is rigid with respect to the soil and is in full contact with the soil.

The physical meaning of CRR is that any footing having a relative rigidity less than the CRR is in full contact with the soil and the one having the relative rigidity more than CRR suffers loss of contact. The graphs showing the variation of CRR with respect to ,eccentricity to footing width ratio(e/B), for various Poison's ratio of the material of the footing $(\mu)$ and for the practical cases of the column to footing width ratios (c/B) of 0.1,0.2,0.3 and 0.4.

\section{Use of Determination of CRR}

The determination of the CRR values for different conditions would go in a long way in helping the designer of footings in changing either the plan dimensions or the thickness of the footing in such a way that the actual relative rigidity is less than the CRR.

For example,

If a concentrically loaded concrete footing $(\mu=0.15, E=25$ $\mathrm{x}$ 10) of plan dimensions $3 \mathrm{~m} \mathrm{x} 3 \mathrm{~m}$ and thickness $0.5 \mathrm{~m}$ supporting a column of width $0.3 \mathrm{~m}$ (column to footing width ratio $=0.1$ ) is resting on a very hard stratum of modulus of subgrade reaction $8 \times 105 \mathrm{KN} / \mathrm{m} 2$, the actual Relative Rigidity works out to be $\mathrm{R}=3 \Pi$ (3) $4 \times 8 \times 10=195$ 25 x 106x 0

\section{Discussion}

The present results indicating the variation of Critical Relative Rigidity (CRR) with respect to Poisson's Ratio for various eccentricities and column width to footing width ratios.

Eccentricity to width of footing ratio for various Poisson ${ }^{\text {ee }}$ ratio values and column width to footing width ratios.Column width to footing width ratio for various eccentricities and Poisson"s ratio values.

The graph drawn for the variations of $\mathrm{M} / \mathrm{P}$ (Maximum bending moment per unit width per applied load) with respect to $\mathrm{RR}$ for column to footing width ratio 0.2 , eccentricity to footing width ratio 0.0 and Poisson es ratio 0.3 . In this chart conventional bending moment also has been indicated.

The ordinate represents CRR and the absicca represents Poisson "s ratio. As the Poisson"s ratio increases CRR also goes on increasing. Considering a point $\mathrm{A}$ as shown in the figure and another point $\mathrm{D}$ which is marked on the same horizontal line through $\mathrm{A}$. The point a represents the relative rigidity of a footing of Poisson ${ }^{\text {ee }}$ s ratio 0.15 .

It is observed that, as the RR increases bending moment decreases. The bending moment given by conventional method is shown as a horizontal line. If a compression is made between the maximum bending moment given by the ANSYS and that given by the conventional method, for low values of RR maximum bending moment given by ANSYS is more than that given by conventional method and for higher values of RR maximum bending moment given by ANSYS is less than that of conventional method.

It is observed that the bending moment given by conventional method is less than that given by ANSYS up to a relative rigidity of 3800 and more than that given by ANSYS beyond 3800.It means that the conventional method of estimating 


\section{International Journal of Science and Research (IJSR) \\ ISSN (Online): 2319-7064 \\ Index Copernicus Value (2013): 6.14 | Impact Factor (2015): 6.391}

bending moment at lower values of relative rigidity is unsafe and at higher values of relative rigidity, it is conservative.

\section{Conclusion}

1)The graph drawn for the variations of $M / P($ Maximum bending moment per unit width per applied load) with respect to $\mathrm{RR}$ for column to footing width ratio 0.2 , eccentricity to footing width ratio 0.0 and Poisson ${ }^{\text {ee }}$ ratio 0.3

2)ANSYS 12.0 results show that bending moment depends on relative rigidity of footing also

3) An equation for CRR critical relative rigidity was derived from the Multiple linear regression analysis.

4) Graphs have been drawn indicating the variation of Critical Relative Rigidity (CRR)
[12] Mehta, P. K. and Monteiro, P.J.M., „Concrete Microstructure, properties, and materials ${ }^{e e}$, (McGrawHill Book Co, New York, 2006).

\section{References}

[1] System (2007) Halil Sezen, M.ASCE; and Mohammad Shamsai "High-Strength Concrete Columns Reinforced with Prefabricated Cage" J.Constr.Eng.Manage (2007)133:864-870

[2] Syed Sohailuddin S S1 and M G Shaikh1 (2013) "FINITE ELEMENT MODELING OF REINFORCED CONCRETE BEAM COLUMN JOINT USING ANSYS" International Journal of Civil and Structural Engineering Volume2, No 3.

[3] Ata EI-kareim Shoeib Soliman(2011) "Behavior of long confined concrete column" Ain Shams Engineering Journal (2011) 2,141-148.

[4] R.Chitra \& R.Thenmozhi (2011) "Studies on prefabricated cage reinforced steelconcrete composite beams" Asian jouranal of civil engineering (building \& housing) vol. 12, no. 1, Pages 27-37.

[5] Mander, J. B., Priestley, M. J. N., and Park, R. (1988). "Theoretical stress-strain model for confined concrete." J. Struct. Eng., 114(8), 1804-1826.

[6] Shamsai, M., and Sezen, H. (2005). "Fast and easy concrete construction using innovative steel reinforcement." Proc., Construction Research Congress, ASCE, Reston, Va., 317-321.

[7] Shamsai, M. (2006). "Prefabricated cage system for reinforcing concrete members."Ph.D. dissertation, Dept. of Civil and Environmental Engineering and Geodetic Sciences, Ohio State Univ., Columbus, Ohio.

[8] Joel Gniel a,1, Abdelmalek Bouazza "Construction of geogrid encased stone columns:A new proposal based on laboratory testing" Geotextiles and Geo membranes 28 (2010) 108-118

[9] Joel Gniel 1, Abdelmalek Bouazza "Improvement of soft soils using geogrid encased stone columns" Geotextiles and Geomembranes 27 (2009) 167-175.

[10] McDowell EL, McKee KE, Sevin E. Arching action theory of restrained masonry walls. ASCE J Struct Eng 1956;82(ST):915-1-915- 18

[11] Neville, A., „Neville on Concrete, An Examination of Issues in Concrete Practice, , American Concrete Institute, 2003). 